\title{
Electrospinning of Highly Crystalline Polymers for Strongly Oriented Fibers
}

\section{Supporting Information}

\author{
Arnaud W. Laramée, Catherine Lanthier and Christian Pellerin* \\ Département de chimie, Université de Montréal, Montréal, QC, H3C 3J7, Canada \\ * Corresponding author: c.pellerin@umontreal.ca
}


Table S1. Polarity and volatility of the solvents used for electrospinning PEO nanofibers ${ }^{1}$

\begin{tabular}{lccc}
\hline Solvent & $\begin{array}{c}\text { Dielectric } \\
\text { constant } \boldsymbol{\varepsilon}\end{array}$ & $\begin{array}{c}\text { Boiling point } \\
\left({ }^{\circ} \mathbf{C}\right)\end{array}$ & $\begin{array}{c}\text { Vapor pressure } \\
(\mathbf{k P a})\end{array}$ \\
\hline Chloroform $\left(\mathrm{CHCl}_{3}\right)$ & 4.8 & 61.2 & 26.2 \\
Hexafluoroisopropanol (HFIP) & 16.7 & 59 & 21.2 \\
Methanol (MeOH) & 33.0 & 64.5 & 16.9 \\
N,N-dimethylformamide (DMF) & 38.3 & 152.8 & 0.439 \\
Water $\left(\mathrm{H}_{2} \mathrm{O}\right)$ & 80.1 & 100.0 & 3.17 \\
\hline
\end{tabular}

The boiling points, vapor pressures, and dielectric constants are measured at $101.3 \mathrm{kPa}, 25^{\circ} \mathrm{C}$, and $20{ }^{\circ} \mathrm{C}$, respectively. Despite having a boiling point higher than that of $\mathrm{HFIP}, \mathrm{CHCl}_{3}$ has a higher vapor pressure at $25^{\circ} \mathrm{C}$ and is thus considered as the most volatile solvent in this work.

${ }^{1}$ CRC Handbook of Chemistry and Physics. 101st ed.; Rumble, J. R., Ed. CRC Press: Boca Raton, FL: 2020

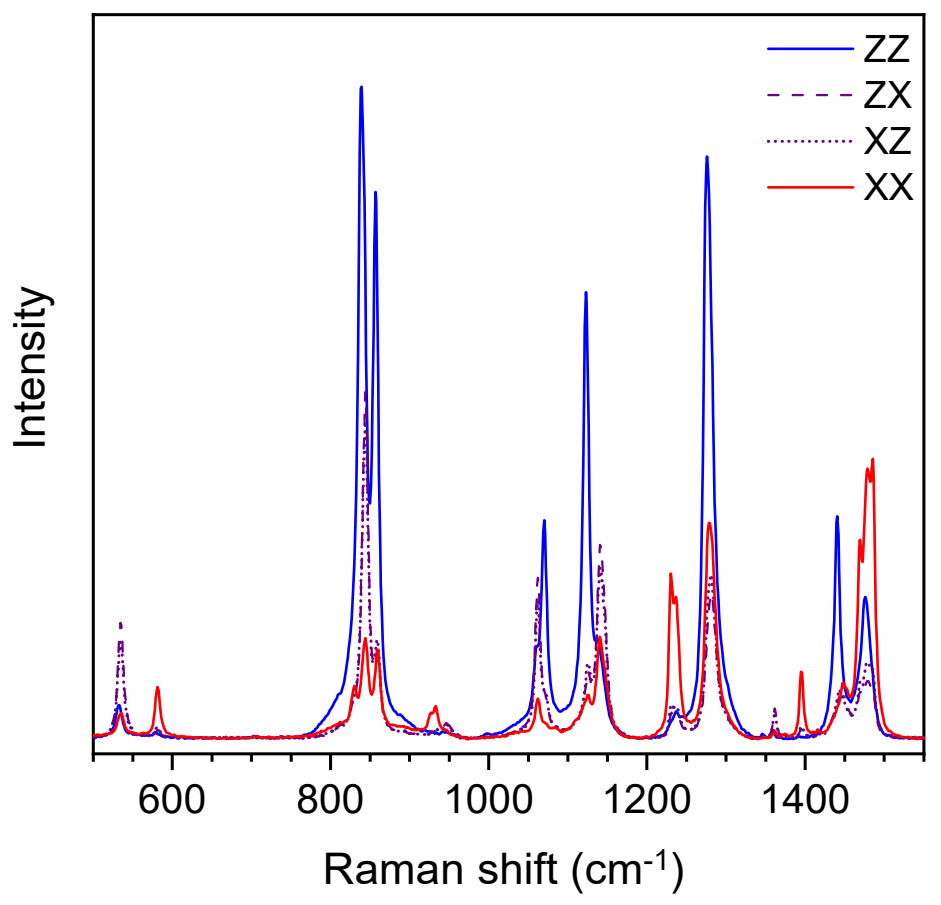

Fig. S1. Set of four polarized Raman spectra (extended spectral range) collected from a PEO fiber with a $\left\langle P_{2}\right\rangle$ of 0.60 and a diameter of $1200 \mathrm{~nm}$. 

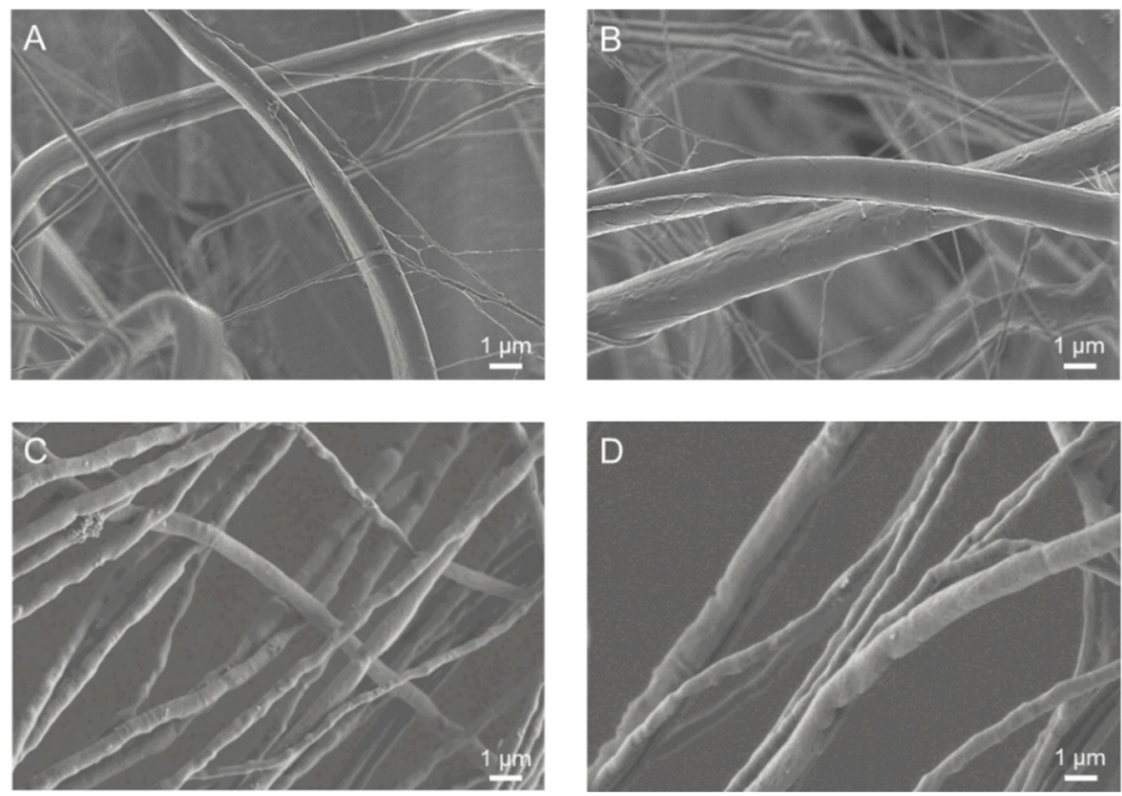

Fig. S2. SEM pictures of PEO nanofibers electrospun using HFIP (A-B) and DMF (C-D). A and C show smaller fibers electrospun from lower concentration solutions while B and D show larger fibers electrospun from higher concentration solutions. The fibers all show a rather smooth surface and a cylindrical shape, including those spun from DMF despite its distinct solvent properties and the lower molecular orientation reached in DMF-spun fibers.

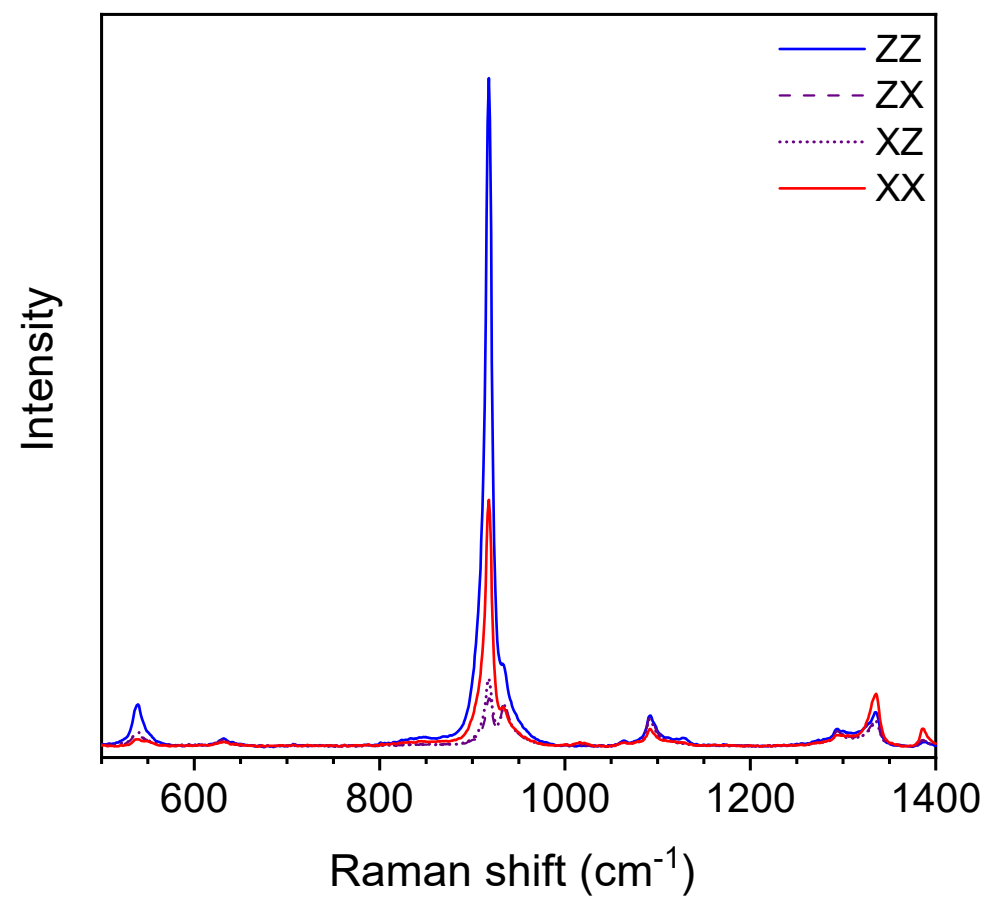

Fig. S3. Set of four polarized Raman spectra collected from a POM fiber with a $\left\langle P_{2}\right\rangle$ of 0.60 and a diameter of $1150 \mathrm{~nm}$. 


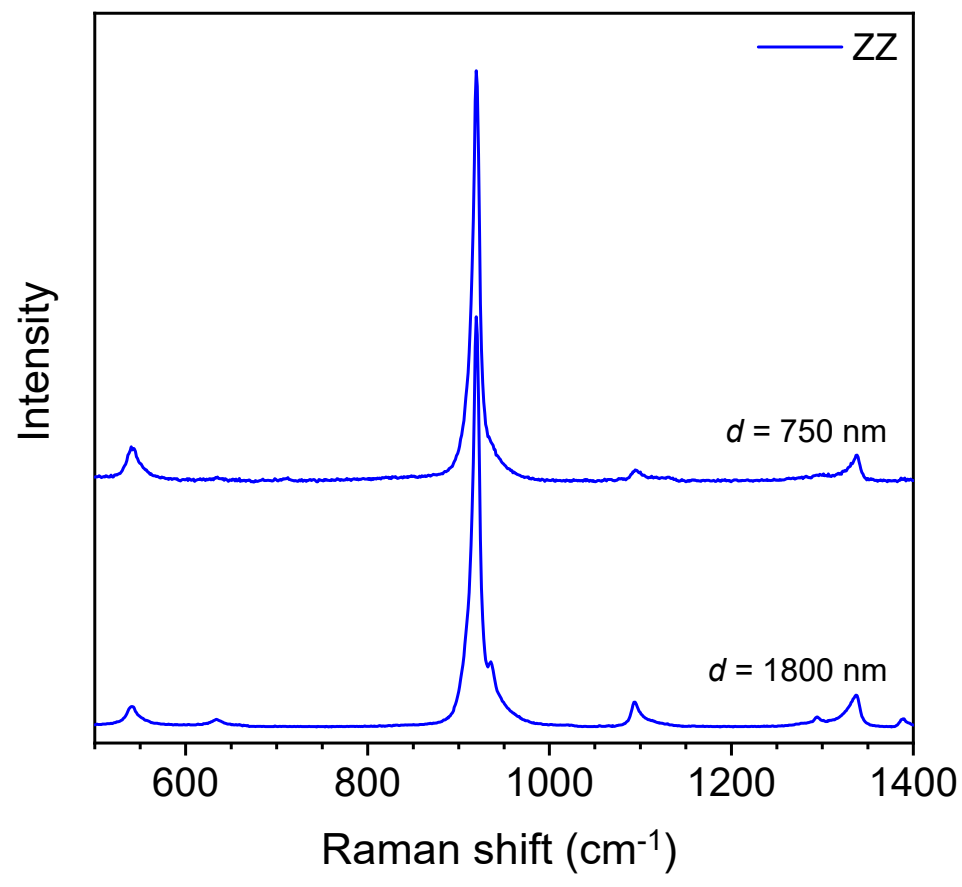

Fig. S4. Polarized Raman spectra of POM fibers with a $\left\langle P_{2}\right\rangle$ of 0.66 and a diameter of $750 \mathrm{~nm}$ (top) and a $\left\langle P_{2}\right\rangle$ of 0.22 and a diameter of $1800 \mathrm{~nm}$ (bottom). Differences in band intensities are due to different level of molecular orientation.

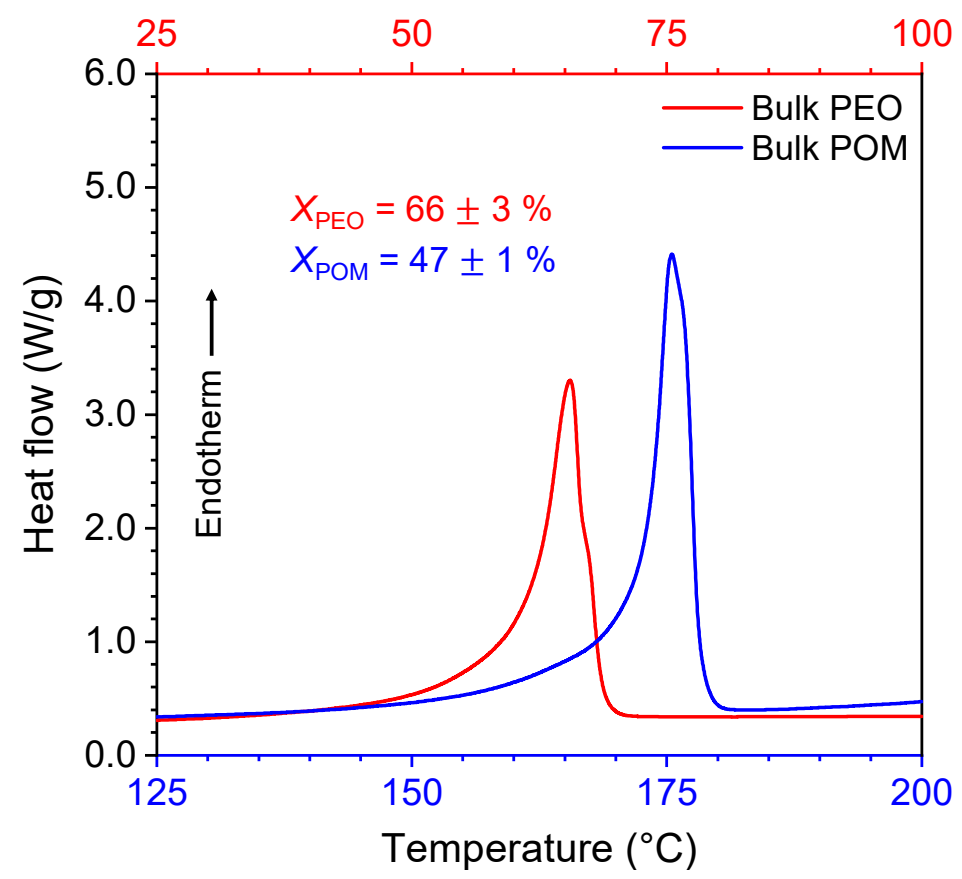

Fig. S5. DSC thermograms corresponding to bulk PEO and POM samples obtained by erasing the thermal history of NF mats followed by a $30 \mathrm{~K} \mathrm{~min}^{-1}$ cooling scan. The relative degrees of crystallinity follow the trend found for PEO and POM NFs in Fig. 5. 